\title{
Autologous Microvascular Breast Reconstruction
}

\author{
Claragh Healy, Venkat Ramakrishnan \\ St. Andrew's Centre for Burns and Plastics, Broomfield Hospital, Chelmsford, UK
}

\begin{abstract}
Autologous microvascular breast reconstruction is widely accepted as a key component of breast cancer treatment. There are two basic donor sites; the anterior abdominal wall and the thigh/buttock region. Each of these regions provides for a number of flaps that are successfully utilised in breast reconstruction. Refinement of surgical technique and the drive towards minimising donor site morbidity whilst maximising flap vascularity in breast reconstruction has seen an evolution towards perforator based flap reconstructions, however myocutaneous flaps are still commonly practiced. We review herein the current methods of autologous microvascular breast reconstruction.
\end{abstract}

Keywords Free tissue flaps / Mammaplasty / Mastectomy
Correspondence: Claragh Healy

St. Andrew's Centre for Burns

and Plastics, Broomfield Hospital,

Chelmsford, CM1 7ET, UK

Tel: +44-77-6671-2451

Fax: +44-12-4546-1569

E-mail: claraghhealy@gmail.com

No potential conflict of interest relevant to this article was reported.

\section{INTRODUCTION}

Breast Reconstruction is a recognised key element to the successful treatment of breast cancer and has become the standard of care in the western world. The National Institute for Clinical Excellence in the United Kingdom stipulates that every woman contemplating a mastectomy must be offered the choice of reconstruction and in the US the government has mandated that insurance providers that offer mastectomy coverage must also provide coverage for reconstructive surgery.

The goal of reconstruction is to fulfil the patients desires, whilst minimising functional and aesthetic donor morbidity and without affecting the oncological management. The reconstructive options are broadly classified into 1) implant-based reconstruction, 2) autologous reconstruction and 3) a combination of both. Here we confine our discussion for autologous microvascular breast reconstruction.

\section{TIMING OF FLAP RECONSTRUCTION}

Breast reconstruction is divided into immediate or delayed, with the recent addition of "delayed-immediate" reconstruction [1]. The advantage of immediate breast reconstruction is both physical and psycholocial. The physical advantage is the preservation of the breast skin envelope and inframammary fold following skin sparing or nipple sparing mastectomy to optimise the aesthetic outcome and numerous studies have confirmed the psychological benefit of immediate reconstruction $[2,3]$. The disadvantage of immediate reconstruction is the uncertainty regarding adjuvant radiotherapy and chemotherapy. The effect of radiation on autologous reconstructed breast has been debated, however there are some reports that suggest irradiation of perforator flaps has been associated with increased incidence of fat necrosis and an inferior aesthetic outcome than not irradiated autologous reconstructions [4-6]. In some institutions a "delayed -immediate" approach is chosen in patients that are likely to require radiotherapy. An expander implants are inserted as a temporary measure to maintain the breast skin envelope and an autologous reconstruction is performed once radiotherapy is complete $[1,6]$. There is also an onus on the reconstructive surgeon that delayed wound healing and wound infection are minimised to prevent disruption of adjuvant treatment regimes.

Copyright $(\odot 2013$ The Korean Society of Plastic and Reconstructive Surgeons

This is an Open Access article distributed under the terms of the Creative Commons Attribution Non-Commercial License (http://creativecommons.org/

licenses/by-nc/3.0/) which permits unrestricted non-commercial use, distribution, and reproduction in any medium, provided the original work is properly cited. 
Delayed reconstructions are also commonly performed in the western world. This population of patients generally fall into two categories; patients who had mastectomy many years previously when reconstruction was not routinely offered or patients who were unwilling or advised against reconstruction at the time of the original surgery. The advantage of delayed reconstruction is that the patient is generally very motivated and their oncological treatment has been completed. The disadvantage is the absence of the skin envelope and scarring secondary to radiotherapy. There are many free flaps described for breast autologous microvascular reconstruction. Those based on the soft tissue of the lower abdominal wall are the most commonly used due to the relative tissue laxity of this area, however there are of number of other flaps based on the tissues of the buttock and thigh area.

\section{ABDOMINAL WALLMICROVASCULAR BREAST RECONSTRUCTION}

The lower abdominal skin and subcutaneous tissue is a wellestablished donor site for autologous breast reconstruction. The deep (DIEA) or superficial inferior epigastric (SIEA) vessels are the donor vessels for the most commonly used flaps. There are three variants of deep inferior epigastric artery based free flaps; the transverse rectus abdominis myocutanoeus (TRAM) flap, the muscle-sparing free TRAM flap and the deep inferior epigastric artery perforator (DIEP) flap. The superficial epigastric artery based SIEA flap is raised without involving the rectus muscle and sheath.

\section{TRAM Flap}

The free TRAM flap for breast reconstruction was first described in 1979 by Holstrom [7]. Both pedicled and free TRAM have being widely used in the past for breast reconstruction, however the free TRAM has superior vascularity, eliminates the upper midline bulge, allows greater freedom to mould and inset the breast flap and limits abdominal wall weakness. The free TRAM flap is composed of the rectus abdominis and the skin and subcutaneous tissue of the lower abdominal wall supplied by the DIEA. Donor morbidity secondary to harvesting the rectus muscle and anterior rectus sheath resulted in a drive towards sparing the muscle as much as possible. Nahabedian has described four variants of the muscle-sparing (MS) TRAM. MSO, full width of the rectus abdominis muscle is sacrificed; MS-1, lateral segment is preserved; MS-2, refers to preservation of lateral and medial segment, and MS-3, refers to preservation of the entire muscle equivalent to DIEP flap. In the muscle-sparing technique (MS1), the innervated lateral rectus muscle is left intact whilst the medial rectus muscle supports the perforators with a narrow strip of anterior sheath is harvested with the flap.

\section{DIEP Flap}

In 1989, Koshima and Soeda [8] first described the harvesting the lower abdominal flap without sacrificing the rectus muscle, in 1992, Allen and Treece [9] successfully performed the first DIEP flap for breast reconstruction. Refinement of technique and increased cumulative experience and the desire to minimise donor morbidity has resulted in the DIEP flap becoming one of the workhorse perforator flaps in breast reconstruction (Fig. 1).

\section{Flap anatomy}

Both TRAM and DIEP flap is based on the deep inferior epigastric vessels. The classic description of the DIEA is that it branches into a medial and lateral row deep to the rectus muscle and these in turn supply branches that penetrate the muscle and supply the overlying skin and soft tissue. Moon and Taylor originally classified the branching pattern of the DIEA as Type 1 (single branch) in 29\%, Type 2 (bifurcating) in 57\% and Type 3 (trifurcating) in $14 \%$ [10]. A recent in vivo study of 500 hemi-abdomens noted a greater number of type 1 (43\%) and lower number of type 3 (9\%), with $48 \%$ demonstrating the type 2 branching pattern [11]. The authors also noted a statistically significant concordance between the sides of a single abdomen when type 1 branching pattern was present.

Following on from the anatomy of the DIEA the tissue of the lower abdominal wall is subdivided into four zones (1-4). The initial description of zones of the abdominal wall, attributed to Hartrampf et al. [12], was based on a unipedicled TRAM flap based on the superior epigastric vessels. In this description zone 1 overlies the ipsilateral muscle, zone 2 the contralateral muscle, zone 3 the ipsilateral lateral quadrant and zone 4 the contralateral lateral quadrant. However in 2006, Holm et al. [13], using

Fig. 1. Deep inferior epigastric artery perforator (DIEP) flap (A) Preoperative finding. (B) Postoperative skin sparing mastectomy and bilateral DIEP flaps.

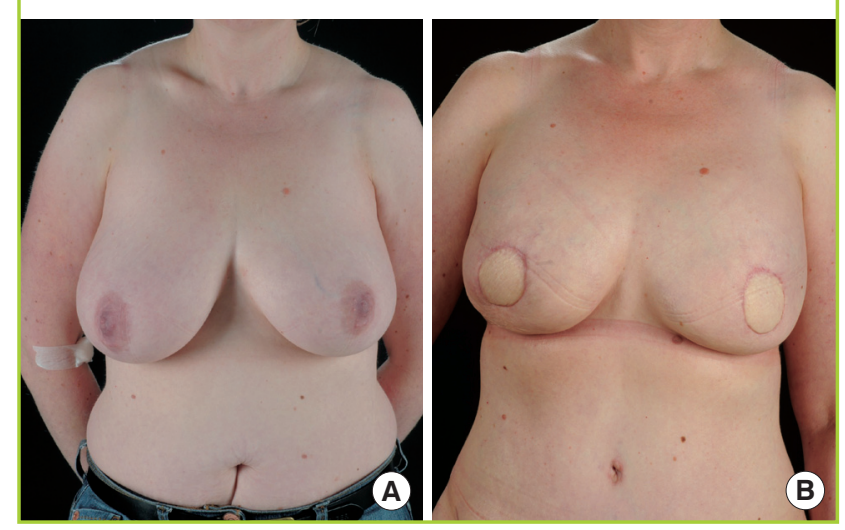


a dynamic technique of perfusion evaluation, demonstrated that switching of Hartrampf zones 2 and 3 more accurately described the perfusion for the DIEP flap and that perfusion of zone 4 is frequently critically reduced and therefore should be discarded. Further work on the perfusion zones of specific perforators of the DIEP flap or perforator angiosomes, has demonstrated fundamental differences between the lateral and medial row perforators; primary zones 1 and 2 of medial row perforators comprise the entire ipsilateral hemiabdomen and routinely cross the midline to perfuse the medial part of the contralateral hemiabdomen, whereas primary zones 1 and 2 for lateral row perforators are more limited and do not routinely perfuse the contralateral hemiabdomen $[14,15]$. Furthermore, the nerves that innervate the rectus abdominis muscle have been shown to enter the posterior surface up to the midpoint of the muscle just medial to the lateral row perforators, therefore harvesting of lateral row perforators may denervate the rectus muscle resulting in abdominal wall morbidity [16].

The choice of perforator is a critical component in obtaining maximum vascularity of the DIEP flap. The studies on angiosomes influence our decision intra-operatively on perforator selection, however the key factor is vessel diameter. In accordance with Hagen-Poiseuille's Law the flow in a tube is related the fourth power of the radius, therefore choosing a single perforator of greatest diameter is far more effective than multiple perforators of a smaller diameter at increasing blood flow $[17,18]$. These studies, along with clinical experience have emphasized the importance of choosing a perforator to achieve optimal vascularisation of the DIEP flap with minimal morbidity. To this end the role of preoperative imaging has become increasingly accepted as a reliable method of delineating perforators; aside from giving a road map it eliminates the urge to preserve the more lateral perforators with a greater use of medial row perforators, shortening operative time and has decreased the incidence of fat necrosis $[19,20]$.

\section{Flap design}

The flap is designed as an ellipse on the lower abdominal wall depending on the laxity of the panniculus, avoiding undue tension on the abdominal wound closure and minimising the caudal displacement of the inframammary crease. The superior umbilicus acts as the upper limit. The lateral limit of the ellipse is the anterior superior iliac spine. Ipsilateral or contralateral-based flaps may be used; however the harvesting of the contralateral flap permits a two-team approach for immediate reconstructions. There are many variations in raising the DIEP flap, in our unit we perform contralateral inferior incision first, preserving the superficial inferior epigastric vessels, then proceed to the superior margin.
The flap is then raised from lateral to medial and once a perforator has been chosen, the anterior rectus fascia is incised and the course of the perforator dissected through the muscle down to the posterior rectus fascia. Once on the posterior rectus fascia the rectus is split longitudinally until sufficient calibre of the pedicle has been obtained. The contralateral side is then elevated and zone 4 discarded. The area under the mastectomy skin flaps is de-epithelialized. The bulky medial flap is used for inferior and medial breast reconstruction, while the lateral part of the flap is placed high up towards the axilla. Superiorly, the flap is sutured to pectoral fascia. The flap can be folded onto itself to increase the projection inferiorly. A circular skin paddle is left to simulate the areola and for nipple reconstruction in the future. The thoracodorsal or internal mammary vessels are used as recipient vessels for anastomosis, depending on the surgeon's preference.

A stacked flap may be used for single breast reconstruction where there is inadequate zone $1-3$ or a lower midline scar $[21,22]$. In the stacked flap two DIEP flaps are raised with linkage of their pedicles and perfusion and a single recipient vessel or alternatively a bipedicled flap where the abdominal tissue is transferred without separating it in to two separate flaps, in this instance two separate recipient vessels may be used or linked [23,24].

After the flap inset, anterior rectus sheath is repaired in two layers to minimize donor site complications and morbidity. The umbilicus is relocated at a level above anterior superior iliac spine. The scarpa's layer is sutured separately, while the abdominal skin is sutured in two layers.

\section{Contraindications and complications}

There are few absolute contraindications to a DIEP flap. Blondeel has stated a non-motivated patient and poor general condition are the only absolute contraindications to DIEP flap reconstruction [25]. In the past previous abdominoplasty, liposuction and active smoking were regarded as absolute contraindications [26]. However technical refinements and preoperative imaging have largely rendered what were once absolute to relative contraindications [27]. Obesity is not a contraindication for surgery itself, however it may increase the anaesthetic related complication, preoperative weight loss in the obese may be of benefit to the surgeon as perforators undergo irreversible dilation with an increase in body weight which is maintained with subsequent weight loss [28].

In 2009, Man et al. [29] published a metaanalysis comparing outcomes following DIEP and Free TRAM flaps [30]. They report double the rate of fat necrosis in DIEP flaps $(10.1 \%$ vs. $4.9 \%)$, and double the rate of total flap loss ( $2 \%$ vs. $1 \%)$, The incidence of abdominal wall bulge, laxity and weakness was double in free TRAMs vs DIEPS (3.1\% vs. $5.9 \%)$, whereas the 
incidence of abdominal herniae was $0.8 \%$ in DIEP compared with $3.9 \%$ in TRAM.

\section{SIEAFlap}

Antia and Buch [31] reported on the transfer of an abdominal dermo-fat graft by direct anastomsis to reconstruct a facial contour deformity as early as 1971 and 20 years later Grotting [32] described it's use in breast reconstruction. The primary advantage of the SIEA is that the anterior rectus sheath is no breached and thus any associated morbidities avoided. However the primary disadvantage is the variability of the vascular anatomy. In addition the flap is limited to zone 1 and 2 of the ipsilateral side and the superficial location of the pedicle as it exits the flap may present problems with inset and moulding of the flap.

\section{Flap anatomy}

The SIEA flap is an axial adipocutaneous flap perfused by a subdermal vascular plexus system. The SIEA artery arises from the femoral artery as a common trunk with superficial circumflex iliac artery (SCIA) in $48 \%$ and independently in $17 \%$ of the cases. The artery has accompanying vena comitantes, an additional prominent vein runs 3 to $4 \mathrm{~cm}$ medial to the artery. In a study of 500 hemiabdomens by Rozen et al. [33] the SIEA was identified in $94 \%$, with a mean diameter of $0.6 \mathrm{~mm}$, only $24 \%$ of cases was of a diameter greater than $1.5 \mathrm{~mm}$. SIEA. In addition they noted SIEA branches directly crossed the abdominal midline in 5\% of cases, with larger SIEA diameters correlated with a decrease in diameter of ipsilateral DIEA perforators.

\section{Flap design}

The flap design of the abdominal donor site is similar to that of the DIEP, as it may be necessary to revert to a DIEP flap should the vascular anatomy be deemed insufficient. Spiegel and Khan [34] propose an algorithm that allows for use of the SIEA only when the vessel is greater than $1.5 \mathrm{~mm}$, with a visible and palpable pulse at the lower abdominal incision. Some advocate trimming of the flap once it has been elevated in it's entirety and a the poorly perfused zones have demarcated. However it is difficult to accurately recognise poor perfusion and drainage when the flap is elevated.

\section{Complications and contraindications}

There is no risk of abdominal hernia or bulge following the flap harvest as the vessels run above the rectus sheath. However the SIEA has not gained widespread acceptance due to the variability of the vasculature, the short pedicle length $7 \mathrm{~cm}$ (range, 6 to $15 \mathrm{~cm})$ and limited flap territory.

\section{Ruben Flap}

Peter Paul Ruben, a 16th century painter, depicted the fat folds over iliac crest prominently in all his female forms. The Ruben flap was described as a method of breast reconstruction for those patients where abdominal tissue was unavailable by Hartrampf [35] in 1994, but has not gained widespread acceptance as a primary breast reconstructive technique. The blood supply arises from a cutaneous perforator from the ascending branch of deep circumflex iliac artery (DCIA) that ascends from the external iliac towards the anterior superior iliac spine. The dissection involves releasing the external oblique, internal oblique and transverses abdominis from the iliac crest [36]. The flap pedicle is 5 to $6 \mathrm{~cm}$ in length and $2.5 \mathrm{~mm}$ in diameter. The disadvantages of Ruben flap are steep learning curve, difficult dissection and paresthesia of the lateral cutaneous nerve of the thigh and improper reinsertion of donor site muscles on the iliac crest can cause postoperative hernia.

\section{BUTIOCKAND THIGH FLAPS}

Where there is insufficient soft tissue laxity of the abdominal wall the buttock and thigh provide for a number of flaps to reconstruct the breast. The gluteal artery perforator flaps (GAP) may be based on the superior (SGAP) or inferior (IGAP) artery, whereas the transverse upper gracilis flap (TUG) is a myocutaneous flap based on the ascending branch of medial circumflex femoral artery. Recently Allen et al. [37] have described the profunda artery perforator (PAP) flap.

\section{GAP Flaps}

Fujino et al. [38] first described the superior gluteal myocutaneous free flap for breast aplasia in 1975. Le-Quang [39] described the inferior gluteal flap in 1992. Both of these techniques have been refined and modified extensively by Allen et al. [40-42], and currently with preoperative imaging they septocutaneous GAP flaps are being performed $[43,44]$.

\section{Flap anatomy}

Both gluteal arteries arise from the internal iliac artery. The superior gluteal artery arises from the posterior division, exits the greater sciatic foramen above the piriformis along with the nerve and divides into deep and superficial branches. The superficial branch supplies perforators to the upper portion of the gluteus maximus along with the overlying skin. The inferior gluteal artery is a branch of the anterior divison of the internal iliac, and exits the pelvis below the piriformis along with the inferior gluteal nerve, the posterior cutaneous nerve of the thigh and the sciatic nerve. The vessel then courses obliquely through the glu- 
teus maximus muscle to supply the lower portion of the buttock.

\section{Flap design}

The SGAP flap is marked in the lateral decbitus position. A line is drawn from the posterior superior iliac spine to the greater trochanter. The junction of the upper and middle $1 / 3 \mathrm{rd}$ of this line generally represents the entrance of perforators into the flap. The skin paddle is orientated obliquely along this line of dimensions up to $10 \times 22 \mathrm{~cm}$. The pedicle length obtained is typically 5 to $8 \mathrm{~cm}$. Allen has recently advocated the use of more lateral perforators for ease of dissection and increased pedicle length, the septocutaneous gluteal atery perforator flap (sc-GAP) [39]. The design of the sc-GAP is centred over the perforator and is more cephalad and lateral than the SGAP, resulting is a more favourable postoperative buttock contour.

The inferior gluteal crease is initially marked in the standing position and the inferior limit of the IGAP flap is $1 \mathrm{~cm}$ inferior to this line. The skin paddle is orientated parallel to the fold, with dimensions up to $7 \times 18 \mathrm{~cm}$. Due to the more oblique course of lateral perforators of the IGA pedicle length between 7 to $10 \mathrm{~cm}$ can be obtained.

\section{Complications and contraindications}

Currently previous liposuction is an absolute contraindication to GAP flaps however with more widespread use of preoperative imaging this may also become a relative contraindication.

Complications related to donor morbidity include contour deformity with the SGAP with up to $20 \%$ requiring revision and tenderness of the scar when sitting for the IGAP. Allen quotes a $2 \%$ flap failure rate [45].

\section{TUG Flap}

The transverse upper gracilis myocutaneous flap (TUG) was first described for breast reconstruction in 2004 [46-48]. It is ideally suited to small to medium breast reconstructions, in patients with minimal abdominal laxity (Fig. 2A, B).

\section{Flap anatomy}

The vascular anatomy of the transverse gracilis flap was investigated by Yousif et al. [49] in 1992. They demonstrated that the proximal pedicle entered the gracilis flap between 8 to $12 \mathrm{~cm}$ below the pubic tubercle and that predominately transverse orientated perforators leave the muscle to supply the overlying skin within $6 \mathrm{~cm}$ of muscle.

\section{Flap design}

Raising the TUG flap is achieved with relative ease and necessitates no intramuscular dissection. It allows for primary nipple reconstruction and the coned flap replicates a non-ptotic breast. Harvesting of the gracilis muscle has minimal functional morbidity and is routinely used in facial reanimation [50].

In our unit the upper border of the flap is located $1 \mathrm{~cm}$ below the groin crease, the anterior limit the femoral artery and posterior the ischial tuberosity. The lower border is designed according to tissue laxity, but in general is between 8 to $12 \mathrm{~cm}$.

The anterior incisons are made initially, just superficial to the fascia, preserving the saphenous vein and associated lymphatics. Once the adductor longus is reached an incision is made through the deep fascia onto the muscle to identify the septum between the adductor and gracilis and where the pedicle is visualised. The posterior incision is then made; remaining superficial to the fascia initially to avoid inadvertent injury of branched of the posterior cutaneous nerve of the thigh. Upon reaching the posterior gracilis, the muscle is encircled inferiorly and with retraction is divided with electrocautery. The cleft between the adductor longus and gracilis is then retracted and the pedicle

\section{Fig. 2. Transverse upper gracilis (TUG) flap}

(A) Preoperative finding. (B) Postoperative skin sparing mastectomy and bilateral TUG flaps. (C) Simultaneous nipple reconstruction.
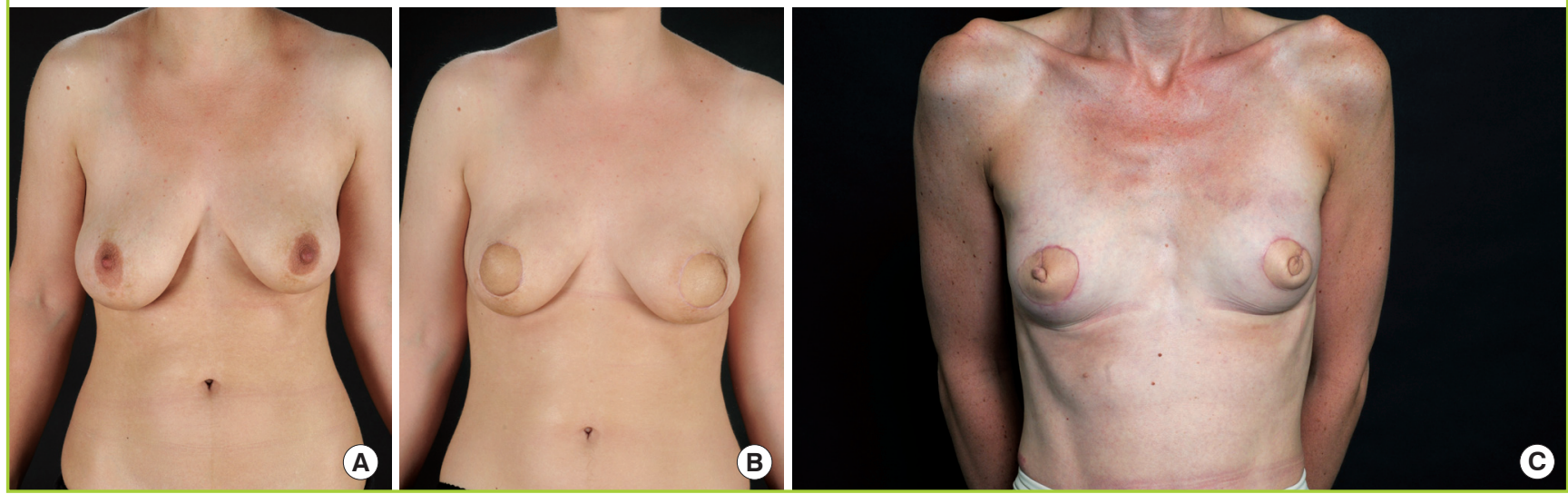
dissected proximally to its origin. The typical pedicle length is 6 to $8 \mathrm{~cm}$, with an arterial diameter of $1.2 \mathrm{~mm}$ [51].

The flap is then coned to recreate the breast mound and the nipple reconstructed from the peak of the cone (Fig. 2C). In our unit we occasionally primarily fat graft the epimysial layer of the muscle to increase flap bulk. The average flap volume harvested reported is approximately $350 \mathrm{~mL}$ [50-52].

\section{Contraindications and complications}

Previous liposuction of the medial thigh is perhaps one of the few contraindications to the TUG flap. The gracilis is a weak adductor of the hip and although functional morbidity in minimal and we have performed bilateral TUG flaps in a horserider, however we would be hesitant to do so in a patient who is a horserider at a high level. The TUG perforator flap had been described, but has not gained widespread use [53].

Complications including donor site dehiscence, seroma, posterior thigh sensory deficit and caudal migration of the scar have all been reported [51]. Preservation of the inguinal lymphatics and saphenous vein are critical to avoiding seroma, lymphorrhea and wound breakdown [50]. Performing a superficial dissection posteriorly will also preserve the branches of the posterior cutaneous nerve of the thigh.

\section{PAP Flap}

Allen et al. [37] have recently described their series of the PAP flap. The flap is based on perforators of the profunda femoris that enter the posterior compartment of the thigh. Preoperative imaging is used to identify the dominant perforator and the flap is centered over this on the posteromedial aspect of the thigh. The upper border of the flap is $1 \mathrm{~cm}$ inferior to the gluteal fold and usually $7 \mathrm{~cm}$ in width and $27 \mathrm{~cm}$ in transverse. The vascular pedicle is identified $3 \mathrm{~cm}$ posterior to the gracilis, average pedicle length was $9.9 \mathrm{~cm}$, artery width $2.2 \mathrm{~cm}$ and vein width $2.8 \mathrm{~cm}$. The advantages cited by the authors relative to the TUG flap are increased pedicle length and avoidance of inguinal lymphatic disruption. Average flap weight was similar to the TUG at $385 \mathrm{~mL}$.

\section{SECONDARY PROCEDURES}

Following breast reconstruction a number of secondary procedures may be required. These include nipple reconstruction and micropigmentation, symmetrising procedures and scar revision where necessary.

\section{REFERENCES}

1. Kronowitz SJ, Robb GL. Radiation therapy and breast re- construction: a critical review of the literature. Plast Reconstr Surg 2009;124:395-408.

2. Atisha D, Alderman AK, Lowery JC, et al. Prospective analysis of long-term psychosocial outcomes in breast reconstruction: two-year postoperative results from the Michigan Breast Reconstruction Outcomes Study. Ann Surg 2008;247:1019-28.

3. Fernandez-Delgado J, Lopez-Pedraza MJ, Blasco JA, et al. Satisfaction with and psychological impact of immediate and deferred breast reconstruction. Ann Oncol 2008; 19:1430-4.

4. Rogers NE, Allen RJ. Radiation effects on breast reconstruction with the deep inferior epigastric perforator flap. Plast Reconstr Surg 2002;109:1919-24.

5. Makmur L, Lim J, Lim TC. Radiation therapy in immediate breast reconstruction with DIEP flap. Plast Reconstr Surg 2003;112:920-1.

6. Massey MF, Spiegel AJ, Levine JL, et al. Perforator flaps: recent experience, current trends, and future directions based on 3974 microsurgical breast reconstructions. Plast Reconstr Surg 2009; 124:737-51.

7. Holstrom $H$. The free abdominoplasty flap and its use in breast reconstruction: An experimental study and clinical case report. Scand J Plast Reconstr Surg 1979;13:423-7.

8. Koshima I, Soeda S. Inferior epigastric artery skin flaps without rectus abdominis muscle. Br J Plast Surg 1989;42:645-8.

9. Allen RJ, Treece P. Deep inferior epigastric perforator flap for breast reconstruction. Ann Plast Surg 1994;32:32-8.

10. Moon HK, Taylor GI. The vascular anatomy of rectus abdominis musculocutaneous flaps based on the deep superior epigastric system. Plast Reconstr Surg 1988;82:815-32.

11. Rozen WM, Ashton MW, Grinsell D. The branching pattern of the deep inferior epigastric artery revisited in-vivo: a new classification based on CT angiography. Clin Anat 2010; 23:87-92.

12. Hartrampf CR, Scheflan M, Black PW. Breast reconstruction with a transverse abdominal island flap. Plast Reconstr Surg 1982;69:216-25.

13. Holm C, Mayr M, Hofter E, et al. Perfusion zones of the DIEP flap revisited: a clinical study. Plast Reconstr Surg 2006;117: 37-43.

14. Rozen WM, Ashton MW, Le Roux CM, et al. The perforator angiosome: a new concept in the design of deep inferior epigastric artery perforator flaps for breast reconstruction. Microsurgery 2010;30:1-7.

15. Wong C, Saint-Cyr M, Mojallal A, et al. Perforasomes of the DIEP flap: vascular anatomy of the lateral versus medial row perforators and clinical implications. Plast Reconstr Surg 2010;125:772-82.

16. Rozen WM, Ashton MW, Murray AC, et al. Avoiding dener- 
vation of rectus abdominis in DIEP flap harvest: the importance of medial row perforators. Plast Reconstr Surg 2008; 122:710-6.

17. Blondeel PN. Discussion: Perfusion-related complications are similar for DIEP and muscle-sparing free TRAM flaps harvested on medial or lateral deep inferior epigastric artery branch perforators for breast reconstruction. Plast Reconstr Surg 2011;128:590e-2e.

18. Rubino C, Ramakrishnan V, Figus A, et al. Flap size/flow rate relationship in perforator flaps and its importance in DIEAP flap drainage. J Plast Reconstr Aesthet Surg 2009;62: 1666-70.

19. Hijjawi JB, Blondeel PN. Advancing deep inferior epigastric artery perforator flap breast reconstruction through multidetector row computed tomography: an evolution in preoperative imaging. J Reconstr Microsurg 2010;26:11-20.

20. Masia J, Navarro C, Clavero JA, et al. Noncontrast magnetic resonance imaging for preoperative perforator mapping. Clin Plast Surg 2011;38:253-61.

21. Ali RS, Garrido A, Ramakrishnan V. Stacked free hemi-DIEP flaps: a method of autologous breast reconstruction in a patient with midline abdominal scarring. Br J Plast Surg 2002; 55:351-3.

22. Blondeel PN, Boeckx WD. Refinements in free flap breast reconstruction: the free bilateral deep inferior epigastric perforator flap anastomosed to the internal mammary artery. $\mathrm{Br}$ J Plast Surg 1994;47:495-501.

23. Agarwal JP, Gottlieb LJ. Double pedicle deep inferior epigastric perforator/muscle-sparing TRAM flaps for unilateral breast reconstruction. Ann Plast Surg 2007;58:359-63.

24. Dellacroce FJ, Sullivan SK, Trahan C. Stacked deep inferior epigastric perforator flap breast reconstruction: a review of 110 flaps in 55 cases over 3 years. Plast Reconstr Surg 2011; 127:1093-9.

25. Blondeel PN. One hundred free DIEP flap breast reconstructions: a personal experience. Br J Plast Surg 1999;52:104-11.

26. Granzow JW, Levine JL, Chiu ES, et al. Breast reconstruction with the deep inferior epigastric perforator flap: history and an update on current technique. J Plast Reconstr Aesthet Surg 2006;59:571-9.

27. De Frene B, Van Landuyt K, Hamdi M, et al. Free DIEAP and SGAP flap breast reconstruction after abdominal/gluteal liposuction. J Plast Reconstr Aesthet Surg 2006;59:1031-6.

28. Shayan R, Rozen WM, Bernard S, et al. Perforator dilatation induced by body weight gain is not reversed by subsequent weight loss: implications for perforator flaps. Plast Reconstr Surg 2008; 122:1765-72.

29. Man LX, Selber JC, Serletti JM. Abdominal wall following free TRAM or DIEP flap reconstruction: a meta-analysis and critical review. Plast Reconstr Surg 2009;124:752-64.

30. Selber JC, Bergey M, Sonnad SS, et al. Free flap breast reconstruction in advanced age: is it safe? Plast Reconstr Surg 2009; 124:1015-22.

31. Antia NH, Buch VI. Transfer of an abdominal dermo-fat graft by direct anastomosis of blood vessels. Br J Plast Surg 1971;24:15-9.

32. Grotting JC. The free abdominoplasty flap for immediate breast reconstruction. Ann Plast Surg 1991;27:351-4.

33. Rozen WM, Chubb D, Grinsell D, et al. The variability of the Superficial Inferior Epigastric Artery (SIEA) and its angiosome: A clinical anatomical study. Microsurgery 2010;30:386-91.

34. Spiegel AJ, Khan FN. An Intraoperative algorithm for use of the SIEA flap for breast reconstruction. Plast Reconstr Surg 2007;120:1450-9.

35. Hartrampf CR Jr, Noel RT, Drazan L, et al. Ruben's fat pad for breast reconstruction: a peri-iliac soft-tissue free flap. Plast Reconstr Surg 1994;93:402-7.

36. Gardner PM, Grotting JC. Rubens flap for breast reconstruction. In: Strauch B, Vasconez LO, Hall-Findlay EH, et al., editors. Grabb's encyclopedia of flaps; torso, pelvis and lower extremities. 3rd ed. Philadelphia: Lippincott Williams \&Wilkins; 2009. p. 1075-7.

37. Allen RJ, Haddock NT, Ahn CY, et al. Breast reconstruction with the profunda artery perforator flap. Plast Reconstr Surg 2012;129:16e-23e.

38. Fujino T, Harasina T, Aoyagi F. Reconstruction for aplasia of the breast and pectoral region by microvascular transfer of a free flap from the buttock. Plast Reconstr Surg 1975;56: 178-81.

39. Le-Quang C. Secondary microsurgical reconstruction of the breast and free inferior gluteal flap. Ann Chir Plast Esthet 1992;37:723-41.

43. Tuinder S, Chen CM, Massey MF, et al. Introducing the septocutaneous gluteal artery perforator flap: a simplified approach to microsurgical breast reconstruction. Plast Reconstr Surg 2011;127:489-95.

40. Allen RJ. The superior gluteal artery perforator flap. Clin Plast Surg 1998;25:293-302.

41. Allen RJ, Levine JL, Granzow JW. The in-the-crease inferior gluteal artery perforator flap for breast reconstruction. Plast Reconstr Surg 2006;118:333-9.

42. Allen RJ, Tucker C Jr. Superior gluteal artery perforator free flap for breast reconstruction. Plast Reconstr Surg 1995;95:1207-12.

44. Granzow JW, Levine JL, Chiu ES, et al. Breast reconstruction 
with gluteal artery perforator flaps. J Plast Reconstr Aesthet Surg 2006;59:614-21.

45. LoTempio MM, Allen RJ. Breast reconstruction with SGAP and IGAP flaps. Plast Reconstr Surg 2010;126:393-401.

46. Schoeller T, Wechselberger G. Breast reconstruction by the free transverse gracilis (TUG) flap. Br J Plast Surg 2004;57:481-2.

47. Wechselberger G, Schoeller T. The transverse myocutaneous gracilis free flap: a valuable tissue source in autologous breast reconstruction. Plast Reconstr Surg 2004;114:69-73.

48. Arnez ZM, Pogorelec D, Planinsek F, et al. Breast reconstruction by the free transverse gracilis (TUG) flap. Br J Plast Surg 2004;57:20-6.

49. Yousif NJ, Matloub HS, Kolachalam R, et al. The transverse gracilis musculocutaneous flap. Ann Plast Surg 1992;29:
482-90.

50. Fattah A, Figus A, Mathur B, et al. The transverse myocutaneous gracilis flap: technical refinements. J Plast Reconstr Aesthet Surg 2010;63:305-13.

51. Schoeller T, Huemer GM, Wechselberger G. The transverse musculocutaneous gracilis flap for breast reconstruction: guidelines for flap and patient selection. Plast Reconstr Surg 2008;122:29-38.

52. Fansa H, Schirmer S, Warnecke IC, et al. The transverse myocutaneous gracilis muscle flap: a fast and reliable method for breast reconstruction. Plast Reconstr Surg 2008;122: 1326-33.

53. Hallock GG. Further experience with the medial circumflex femoral (GRACILIS) perforator free flap. J Reconstr Microsurg 2004;20:115-22. 